\title{
The Interaction between Intelligence Operations and Ethics in the Context of National Security: a Theoretical Review of the Problem***
}

The effectiveness of intelligence operations is directly related to the conduct of intelligence officers and depends on their moral attitudes and system of values. The specifics of intelligence operations may lead to moral dilemmas in the behaviour of the officers. The operating methods of intelligence institutions include both ethical tactical elements and those that run counter to the generally accepted ethical principles that could discredit democracy and the fundamental values that the state advocates. This article analyses the ethical problems that are encountered in the process of using HUMINT, an intelligence method. The authors employ theoretical analysis to construct an initial integral behaviour model of the intelligence officer based on the context of choices and operational implications that could encourage further scientific discussion of the subject.

\section{Introduction}

The threats to the national security of democratic states that are growing exponentially in the modern world are forcing the heads of states and politicians to engage in a continuous assessment of the activities of institutions directly responsible for combating threats to the state and its interests. Different states command their own specific institutional models for assuring national security, yet one could say that in every state, intelligence institutions

\footnotetext{
" Dr. Audrone Petrauskaité, is an associate professor of the Humanities Department, Military Academy of Lithuania. Address for correspondence: Šilo 5a, LT-10322 Vilnius, Lithuania; tel.: +370 5 2103567, e-mail: audrone.petrauskaite@gmail.com.

${ }^{* *}$ Laurynas Šaltenis is a lecturer of the Humanities Department, Military Academy of Lithuania. Address for correspondence: Šilo 5a, LT-10322 Vilnius, Lithuania; tel.: +370 5 2103567, e. mail: laurynas.saltenis@ gmail.com

${ }^{* * *}$ The views of the authors presented in this article do not represent the official position of the intelligence institutions and other bodies in charge of national security of the Republic of Lithuania. The article aims to encourage a moral discussion of the various aspects of intelligence operations.
} 
that, to paraphrase Sun Tzu's saying, ${ }^{1}$ are the eyes and ears of the state, play a large part in ensuring national security. The strategies of national security that states are designing and improving today raise an increasing number of tasks for intelligence institutions and therefore the scope of collecting information of interest to intelligence services has increased significantly in the $21^{\text {st }}$ century. This development has expanded the field of work for intelligence services in collecting intelligence information on international terrorism, weapons trafficking, contraband, the intelligence operations of hostile states and even ecological threats to the state.

After the 9/11 act of terror in the US and a series of terrorist attacks elsewhere in the world, the spotlight of political and social attention has been trained on the operations of intelligence services. The role these institutions play in fighting international terrorism has sparked a discussion among the academic public and former veteran intelligence officers regarding the conduct of intelligence officers in relation to both the ethics of intelligence operations and the national security interests of a state. Even though the International Intelligence Ethics Association (IIEA), which was founded back in 2005, has recently suspended its activities, the discourse of the academic public dealing with the problem of the relations between intelligence operations and ethics never stopped. On the other hand, this discourse still needs a clear-cut framework that would provide the conditions for a structured discussion and scientific and applied research, their outcomes serving as a tool in shaping the operational principles and effectiveness of intelligence services as organisations.

The effectiveness of intelligence institutions as organisations is directly linked to the conduct of intelligence officers, their moral attitudes and systems of values. To ensure the security of a democratic state, the methods of intelligence and counterintelligence operations of these institutions include both ethical tactical elements and those that run counter to the generally accepted ethical principles that could discredit democracy as such and the fundamental values that the state advocates. These elements are particularly evident in the application of the HUMINT (human intelligence) method, for it involves the development of relations between intelligence officers and their human sources of information. These relations are moulded by the intelligence officers using the ethical norms and moral attitudes and models of behaviour of their choice or as prescribed by the intelligence institution.

Ergo, the context of an intelligence institution as an organisation affects the behaviour models that its staff choose. These implications of conduct are

${ }^{1}$ Sun Tzu, Karo menas, Media Incognito, 2006, p. 119-120. 
connected to three levels that can be identified in the theory of organisational behaviour: those of an individual, group and organisation. By virtue of the role they play, the operations of intelligence institutions are inseparable from the level of the state for they directly follow the interests of the state. Following these attitudes, analysis of the subject of the conduct of intelligence officers for research purposes may draw the conclusion that the implications of the behaviour of every individual on the organisational level reflect implications at the state level. This makes the need to raise knowledge and understanding of the models of intelligence officers' behaviour, their expression, causal relationships and impact self-evident. At the same time, due to the specifics of intelligence operations, the conditions to carry out research and empirical studies in particular are quite limited. It could be for these reasons that the analysis of the operations of intelligence institutions by Lithuanian researchers focus on the history of intelligence (Arvydas Anušauskas), intelligence systems, operating methods and results, the mutual influence of intelligence and political institutions (Vaidotas Urbelis), the impact of intelligence services on the foreign policy and diplomacy of the state (Algimantas Kasparavičius) and other relevant similar topics. This tendency can be observed when it comes to the analysis of articles by foreign authors as well, which points to a shortage of sources that would provide a structured analysis of the issue of officer conduct in the context of national security. Still, the limited possibilities to research this subject and related issues make it nonetheless relevant.

To make a contribution to closing the identified gap, this article aims to reveal the expression of the operational context of intelligence officers, pinpointing the key assumptions that potentially affect officers' moral reasoning and behavioural strategies of choice, as well as their implications. To that end, a theoretical analysis of scientific sources in an interdisciplinary context has been conducted. The article presents assumptions regarding intelligence officers' choice of moral reasoning and behavioural strategies, emphasising the specifics of context; discusses possible behavioural strategies of officers and their expression; and dissects examples of the implications of officers' chosen models of behaviour. To sum up, the article closes with an outline of potential directions and recommendations for further academic and practical discourse. 


\section{Operations of Intelligence Institutions and Assump- tions of Officer Conduct}

The tasks of the intelligence service as a governmental institution protecting the interests of national security are directly linked to the political objectives of the state and its foreign policy first and foremost. Lithuania's intelligence services (the State Security Department and the Second Investigation Department under the Ministry of National Defence of the Republic of Lithuania) have their operations regulated by the Intelligence Law, which defines the goals, objectives, principles, methods, organisational and control mechanisms of intelligence ${ }^{2}$. The legal regulation of intelligence operations prescribes the scope of legal responsibility for the intelligence institutions, and the ethical and political aspects of intelligence operations are usually are left out due to their specifics relating to things like classified information or special working methods. On the other hand, even the slightest mix-up pertaining to the operations of intelligence institutions or misconduct on the part of their personnel would cause huge reverberations amongst society, which illustrates the high moral requirements the people place on the operations of intelligence institutions. The public's enormous attention to and interest in the intelligence services is the product of the goal and operational objective of these institutions, which is to ensure the security of the country and its people - in other words, the security interests of all citizens.

Despite the clear mission of the intelligence institutions, national security as an object of intelligence operations is a hard-to-define and ever-shifting concept, one that may cause certain dilemmas in intelligence operations. According to David A. Baldwin, in modern society, national security interests are more often associated with internal and foreign policy issues than with most of the national security concept ${ }^{3}$ and therefore when it comes to dealing with national security matters, in addition to the traditional threats to national security (exterior military threats), economic interests, crime, social injustice, human rights and other types of threats are prioritised too. Notably, in the $21^{\text {st }}$ century, exterior military threats, being the traditional threats to the national security of a country, are also undergoing significant transformation, with asymmetrical threats increasing and traditional military threats transforming

\footnotetext{
${ }^{2}$ The Law on Intelligence of the Republic of Lithuania. 17 July 2000 No VIII-1861 (effective summary wording of 01/01/2017), https:/www.e-tar.lt/portal/lt/legalAct/TAR.1881C195D0E2/MiWMKXwfpy, 08/10/2017.

${ }^{3}$ Baldwin, D.A., "The Concept of Security", Review of International Studies, 1997, 23, p. 9-11.
} 
from conventional to hybrid, thus erasing the boundaries between exterior and interior threats.

The relationship between intelligence and politics is a two-way street. The fast pace of development of modern society is driving rapid change in the nature of threats and risks. With national interior and foreign policy geared towards mitigating the changing threats and risks, the operating priorities of governmental institutions, intelligence institutions included, are shifting as well. The goal of intelligence institutions is to collect information on contemporary threats, dangers and risks to the national security of the country, issue information to the institutions tasked with ensuring national security, and eliminate the threats ${ }^{4}$. In the words of Urbelis, the law 'accentuates the tight connection between intelligence information and foreign policy, and ' $/ . . /$ intelligence information bears exceptional importance in formulating foreign policy steps' The Law on Intelligence of the Republic of Lithuania emphasises that intelligence information affects the shaping of foreign and interior policy priorities, which means that intelligence services as the most informed governmental institutions basically affect the politics of the state to a significant degree in their own right when they release information on threats to national security. The product of the direct ties between national security and the political interests of the state is that national security as the defence of the sovereignty and interests of the state is first of all a matter of values and their priorities. The influence that intelligence services have on the goals and objectives of the interior and foreign policy of the state makes them politically, legally and morally responsible in direct relation to values - the general (prevalent) convictions regarding the importance of standard desirable conduct or the end result ${ }^{6}$.

The scientific ties between values and politics are variegated. Alvydas Jokubaitis argues that politics does not carry independent values, as 'every political decision depends on moral, religious, legal or economic values ${ }^{77}$ and therefore 'political significance can be attached to each and every non-political

\footnotetext{
${ }^{4}$ The Law on Intelligence of the Republic of Lithuania. 17 July 2000 No VIII-1861 (effective summary wording of 01/01/2017), https://www.e-tar.lt/portal/lt/legalAct/TAR.1881C195D0E2/MiWMKXwfpy, $08 / 10 / 2017$.

${ }^{5}$ Urbelis, V., "Lithuanian Intelligence System”, Lithuanian Annual Strategic Review, 2008, p. 208.

${ }^{6}$ Edwards, J. R., Cable, D. M., “The Value of Value congruence”, Journal of Applied Psychology, 2009, May; 94(3), p. 654; Meglino, B. M., Ravlin, E. C., "Individual Values in Organizations: Concepts, Controversies, and Research", Journal of Management, June 1998; 24(3), p. 351-89; Schwartz, S. H., Universals in the Content and Structure of Values: Theoretical Advances and Empirical Tests in 20 Countries, Advances in Experimental Social Psychology, Academic Press, 1 January 1992, 25, p. 1-65; Rokeach, M., The Nature of Human Values, Free press, 1973.

${ }^{7}$ Jokubaitis, A., "Politika be vertybių", Politologija, 2008, No 1 (49), p. 26.
} 
value that we foster's. In the opinion of Ainis Razma, 'all values that society recognises are political', because ' $/ . . /$ the adjective 'political' describes the scope of application of a value rather than its nature'. The different interpretations of the relationship between politics and values do not negate the value aspect of politics; therefore, the operations of intelligence services are first and foremost driven by value-based priorities that define the limits of the moral responsibility of intelligence institutions and cause moral dilemmas in these operations.

Ensuring the security of the state and the public, still the cornerstone operational objective of intelligence operations, makes national intelligence services and their employees morally responsible in executing their service tasks and renders the moral aspect of institutional operations and individual behaviour relevant. For these reasons, in recruiting and hiring individuals, intelligence institutions set the bar in terms of moral requirements for the candidates very high indeed, evaluating their reliability, responsibility, integrity, diligence and other moral characteristics. On the other hand, the work of intelligence institutions is difficult to define and assess in terms of ethics. First of all, the outcomes of intelligence operations might not always be appraised unambiguously due to the ties between intelligence and politics that were mentioned above: the assessment of the work of intelligence services and their personnel depends on the political operating priorities that tend to change on a regular basis. Second, the secrecy of intelligence operations, which has to do with the specifics of the work, restricts the possibilities to get to know all of the methods and tools of such work. This principle defines the narrow scope of an objective discourse that is largely contributed to only by assessments from the former employees of different services. This type of feedback sometimes carries statements that intelligence and ethics do not mix by nature, which illustrates the need to transgress moral attitudes as perceived by the personnel. Even though these testimonies, unfortunately, do not rise to the level of academic research, they show an unambiguous and many-layered assessment of the situation in terms of values to be a significant part of the operational context of security institutions and their personnel.

It is the supreme authorities that shape the goals and objectives of the intelligence service that are rooted in the national interests. In the words of Samuel P. Huntington, 'national interests are public safety and material wellbeing, on the one hand, and on the other - ensuring moral principles and

\footnotetext{
${ }^{8}$ Ibidem, p. 28.

${ }^{9}$ Razma, A., “Apie politiką ir vertybes", Politologija, 2009, No 1 (53), p. 22.
} 
ethical values' ${ }^{\prime 10}$. This means that the national interest per se in a sense makes it necessary for intelligence institutions to abide by ethical requirements in carrying out their fundamental mission of ensuring national security. The key operational principle of the intelligence service - tell the truth ${ }^{11}$ - is the cornerstone moral principle in the relationship between the intelligence officer and the intelligence institution, and between the intelligence institution and national decision-makers. The tell-the-truth rule is a guarantee that confidence in the intelligence institution will be assured; furthermore, it obligates the intelligence institution and its officers to carry out their professional duty of ensuring national security in good faith.

The conduct of intelligence officers is inseparable from the working methods that apply in the operations of intelligence institutions as well as other factors on the individual, group and organisation levels that determine the specific model of behaviour that the officer chooses. Notably, the specifics of work at these institutions prevent the discussion of all of the relevant factors that potentially affect the model of an officer's behaviour, yet there are those who can be relied on for the purposes of a primary scientific analysis. Since questions of morality arise when the decisions and actions an individual makes and takes of their own free will have a positive or negative effect on others ${ }^{12}$, this article aims to discuss the operational context in which there is room for freedom in the officer's decisions and actions, and the implications of the operations could range from a positive effect to potential harm to others. For this purpose, the analysis follows a working method that is potentially connected to moral dilemmas and affects officers' behaviour and its outcomes at the individual, group, organisation and state levels.

There are many different methods of intelligence that depend on the national security priorities of a state, the tasks assigned to the intelligence service, the available technological level and the competences of the governmental institutions involved in the process of intelligence. It is the intelligence community of every state that decides which intelligence methods will be used in its work. For instance, the SID of the Lithuanian NMD provides a list of ten potential intelligence methods ${ }^{13}$ : open source intelligence (OSINT); agency, or human intelligence (HUMINT); signals intelligence (SIGINT); communications intelligence (COMINT); electronic intelligence (ELINT); cybernetic intelligence (CYBERINT); imagery intelligence (IMINT); radar intelligence (RADINT);

\footnotetext{
${ }^{10}$ Huntington, S. P., “The Erosion of American National Interests”, Foreign Affairs, vol 76, issue: 5, 1997, p. 30.

${ }^{11}$ Godfrey, D. E., "Ethics and Intelligence", Foreign Affairs, Vol 56, Issue 3, 1978, p. 630

${ }^{12}$ Velasquez, M. G., Rostankowski, C., Ethics, theory and practice, Englewood Cliffs, NJ: Prentice-Hall.

${ }^{13} \mathrm{https} / / / \mathrm{kam} . \mathrm{lt} / \mathrm{lt} / \mathrm{struktura}$ _ir_kontaktai_563/kas_institucijos_567/aotd/veikla_2156.html, 08/10/2017.
} 
acoustic intelligence (ACINT); and measurement and signature intelligence (MASINT). However, the US Office of the Director of National Intelligence only enumerates six main methods of intelligence ${ }^{14}$ : SIGINT, IMINT, MASINT, HUMINT, OSINT and geospatial intelligence (GEOINT). Traditionally, intelligence operations have relied on human resources. The technological boom that started after World War II gave a lot of promise to the leaders of states and intelligence agencies that intelligence would be able to allow them to abandon the highly problematic conventional operating methods that involved work with human resources. The technology offered an opportunity to see and hear remote intelligence targets, pinpoint GIS data with high precision, intercept signals as they are being broadcast, covertly monitor electronic equipment, and watch, gather and organise different information of interest to intelligence services. The technological advancements, which has made it past the threshold of the $21^{\text {st }}$ century, are making fast headway; however, in addition to helping intelligence gather information, technology also allows the enemy to mask and conceal its actions. What is more, intelligence services were simply not prepared for the enormous amounts of data collected using technological tools. As John Hughes-Wilson put it, "anyone can count ships, tanks or airplanes - but determining an adversary's true plans or intentions is fiendishly difficult to measure or quantify" ${ }^{\prime 5}$. Therefore, even those intelligence communities (meaning institutions involved in the intelligence process) that succumbed to so-called 'technological romance' were quick to admit that when it comes to intelligence, no technology would be able to replace human resources despite all of their flaws and virtues.

HUMINT, agency or human source intelligence, the oldest method of intelligence and still the main pillar of intelligence for many states around the globe $^{16}$, is directly related to the need for the officer to choose a model of behaviour based on the operational context. While all of the other intelligence methods involve technology and the opportunities to employ it, under the HUMINT method information is obtained from human sources ${ }^{17}$, the intelligence officer working directly with a person. This method also includes various actions of the intelligence officer with regard to human sources ${ }^{18}$. With

\footnotetext{
${ }^{14}$ https://www.dni.gov/index.php/what-we-do/what-is-intelligence, 08/10/2017.

${ }^{15}$ Hughes-Wilson, J., On Intelligence, Constable, 2016, p. 56.

${ }^{16}$ Operations Security. Intelligence threat handbook, Section 2, The Interagency OPSEC Support Staff, 1996, Federation of American Scientists, https://fas.org/irp/nsa/ioss/threat96/part02.htm, 12/03/2017.

${ }^{17}$ https://www.dni.gov/index.php/what-we-do/what-is-intelligence, 08/10/2017.

${ }^{18}$ Operations Security. Intelligence threat handbook, Section 2, The Interagency OPSEC Support Staff, 1996, Federation of American Scientists, https://fas.org/irp/nsa/ioss/threat96/part02.htm.
} 
the HUMINT method the intelligence officer works with people who are "the most treacherous, fallible and unreliable source of information of all" 19 , so this method raises the highest number of moral dilemmas both for the employee and the intelligence service in its own right. Application of the HUMINT method follows the overarching assumption that persons with whom cooperation has been or is due to be established need protecting, yet at the same time the intelligence officer may need to tell lies, engage in manipulation, exploitation, provocation, compromising, grafting, blackmailing or exercising other kinds of effects on them ${ }^{20}$. An intelligence officer's as well as a military leader's dual responsibility for their own troops and the local population requires them to shift interpersonal relationships and leadership styles as the situation demand $s^{21}$. Therefore, in starting to use the HUMINT method the intelligence officer is faced with a complicated assessment of the context in terms of values and choosing the right model of behaviour, all the more so as only individuals with very high moral standards are picked for the intelligence service.

As this method of work applies in the context of professional operations based on the interests of the organisation deriving out of the interests of the state, dilemmas of a value-based and ethical nature pop up in the context of interaction between the individual and the organisation. Despite the organisation's definition of the system of values for its members to follow, in making their own decisions individuals adhere to their own values ${ }^{22}$. In scientific literature, the compatibility of the values of an individual and an organisation is analysed through the prism of a congruence of values, which points to the compatibility of the values of an individual and the organisation ${ }^{23}$. A congruence of values can be assessed in two ways: subjectively, to see the extent to which the personal values of an employee match the values of the organisation as perceived by that employee, and objectively, when these values completely mirror the attitude of the organisational community ${ }^{24}$. When it comes to analysing the premises of decisions that intelligence institution personnel choose

\footnotetext{
${ }^{19}$ Hughes-Wilson, J., On Intelligence, Constable, 2016, p. 72.

${ }^{20}$ Endregg M., Intelligence Ethics: Laying a Foundation for the Second Oldest Profession, Handbook of Intelligence Studies, Routledge, 2007, p. 52.

${ }^{21}$ Laurence, J. H.,"Military leadership and the complexity of combat and culture", Military Psychology, 2011 Sep; 23(5), p. 489.

${ }^{22}$ Edwards, J. R., Cable, D.M., “The Value of Value Congruence”, Journal of Applied Psychology, 2009 May; 94(3), p. 654.

${ }^{23}$ Kristof, A. L., "Person-organization fit: An integrative review of its conceptualizations, measurement, and implications", Personnel Psychology, 1996, 49(1), p. 1-49.

${ }^{24}$ Kristof-Brown AL, Zimmerman RD, Johnson EC. “Consequences of Individuals' Fit at Work: a Metaanalysis of Person-Job, Person-Organization, Person-Group, and Person-Supervisor Fit”, Personnel Psychology. 1 June 2005; 58(2):281-342.
} 
to make, subjective assessment might play a critical role, for every employee chooses their own model of behaviour independently. However, analysis of the implications of these models of behaviour requires considering both subjective and objective assessment, because the conduct of an officer and the implications of that conduct in terms of ethics, law and other aspects are scrutinised both by the employee and external assessors (such as their supervisors, the organisational community, the authorities supervising the intelligence services, and society). Therefore, this article's analysis on the premises of decisions that the intelligence officer chooses to make focuses primarily on the subjective assessment - that of the intelligence officer as such.

When it comes to fundamental human values, security is tied in with the pursued security, harmony and stability of society, relationships and oneself ${ }^{25}$. Research shows that in terms of values, two levels of security can be distinguished, one of them relating to personal security, the other to group and social security ${ }^{2627}$. Under the HUMINT method, the intelligence officer is often faced with a dilemma when the security of a group or society requires trampling on personal security, for instance that of one individual. This dualistic nature of values brings forth a dilemma where an employee has at least two choices of models of behaviour. Choice number one involves an assessment of the situation and resolving the moral dilemma based on personal values. Choice number two envisages matching the personal choice to the organisation's system of values and the norms of conduct it implies. Depending on the prevalent culture inside the organisation, in making their choice of model of behaviour, the officer may follow both their own assessment and that of the organisation and/or superiors. Besides that, there is also an option number three, where the employee matches the decision to their own assessment and that of the organisational community and/or superiors.

The psychological aspect of the model of behaviour, or conflict or roles, plays a significant part in shaping the decision-making process of officers. This conflict arises out of a clash between personal expectations and demands and those of others ${ }^{28}$. Moreover, it is driven by a shortage of information of the vague expectations of superiors and peers ${ }^{29}$. In the context of the professional

\footnotetext{
${ }^{25}$ Schwartz, S. H., Boehnke, K., "Evaluating the Structure of Human Values with Confirmatory Factor Analysis", Journal of Research in Personality, 1 June 2004, 38(3), p. 230-55.

${ }^{26}$ Ibid.

${ }^{27}$ Schwartz, S. H., Universals in the Content and Structure of Values: Theoretical Advances and Empirical Tests in 20 Countries, Advances in Experimental Social Psychology, Academic Press, 1992 Jan 1, 25, p. 1-65. ${ }^{28}$ Kahn, R. L., Wolfe, D. M., Quinn, R.P., Snoek, J.D., Rosenthal, R.A., Organizational Stress: Studies in Role Conflict and Ambiguity, Oxford, England: John Wiley.

${ }^{29}$ Ibidem
} 
work of the intelligence officer, conflict may be the product of a clash between the controversial expectations and assessments of the organisational community and the officer's superiors. This controversy is driven by differences in requirements, expectations and opinions among various governmental institutions and/or specialists of different competences.

The decision-making and the behaviour model of the intelligence officer are further affected by the moral norms dictated by and expectations imposed by family and society. As the professional work of the intelligence officer involves a high level of responsibility towards the state, the intelligence officer has to choose between the requirements of the family, society, members of the organisational community and the superiors.

The matter of the priority of values and the problematic character of the assessment of the situation and the possible role conflict have an illustration in the practice of the application of the HUMINT method. Ethical decisions go hand in hand with the prevalent social attitudes towards what is legal and morally acceptable ${ }^{30}$. When the intelligence officer starts interacting with an individual (source) who can supply the required information to them, they have to trample on socially acceptable ethical norms, for instance by lying about themselves, their identity or details about their personal life ${ }^{31}$. In order to obtain the necessary information, the officer may have to manipulate the source without the source knowing it ${ }^{32}$ or use a technique to retrieve the information ${ }^{33}$. Every relationship built between the intelligence officer and a human source becomes fiction regardless of the type of HUMINT actions employed. Since by providing information to the officer, the individual puts himself at risk of personal harm, the information that could help identify the human source is kept in strict confidence. The loss or disclosure of such information could result in the destruction of the individual's reputation or well-being or they may lose their freedom or even their life. Apart from the individual, the intelligence institution may be in jeopardy as well: in that case, the entire HUMINT operations of the institution will be encumbered and the persons who volunteer to provide it with information will have less drive to do so. As a result, protecting the human source is probably the main rule of HUMINT operations.

\footnotetext{
${ }^{30}$ Jones, T., Inadvertent Disclosure of Privileged Information and the Law of Mistake: Using Substantive Legal Principles to Guide Ethical Decision Making, Emory LJ., 1999; 48, p. 1255.

${ }^{31}$ Goldman, J., “Teaching About Intelligence”, Journal of U.S. Intelligence Studies, Vol 20, Number 2, 2013, p. 81 .

${ }^{32}$ Oleszkiewicz S., Eliciting Human Intelligence: A Conceptualization and Empirical Testing of the Scharff Technique, Department of Psychology, University of Gothenburg, Ineko AB, Gothenburg, Sweden, 2016, p. 2. ${ }^{33}$ Kelly, C. E., Miller, J. C., Redlich, A. D., Kleinman, S. M., "A Taxonomy of Interrogation Methods", Psychology, Public Policy, and Law, Vol. 19, American Psychological Association, 2013, p. 170-171.
} 
A paradox, but this rule can be disregarded should decision-makers decide that the national interests outweigh the security of the informer. This type of situation creates ambiguity not only in terms of the moral responsibility of the institution but that of its officers as well. On the one hand, intelligence officers have to protect their human sources of information - that is their professional duty. On the other hand, the officers must execute orders from their superiors. The superiors' demands on the officer to obtain information of interest to the intelligence institution inevitably cause psychological tension, for the objective of avoiding risks and threats to the human source of information runs counter to the pressure on the intelligence officer to obtain information from the source ${ }^{34}$. In cases like that, the relationship between the intelligence officer and their human source of information become an object of the officer's personal moral responsibility, the officer's behaviour and execution strategy, their personal moral dilemma. According to Karl Jaspers, a human being must bear moral responsibility for absolutely every action he or she takes ${ }^{35}$. Ergo, while intelligence officers can share legal and political responsibility with the institution, moral responsibility is not for them to share or delegate.

The context of choice of behavioural model covered above could affect the model of behaviour that the intelligence officer chooses to adopt, which in turn will affect both positive results and negative consequences at the individual, group, organisation and state level. Congruence of values shares a positive link with the outcomes on an individual and organisational level such as a stronger organisational culture, job satisfaction, commitment to the organisation, or extra-role behaviour linked to positive employee attitudes ${ }^{36,37,38}$. On the other hand, a mismatch of values could make an employee feel left out and unable to achieve their full potential, which could eventually be related to job dissatisfaction, low level of engagement, organisational cynicism, poorer

\footnotetext{
${ }^{34}$ Petkus, D. A., "Ethics of Human Intelligence Operations", International Journal of Intelligence Ethics, Vol. 1, No 1, 2010, p. 106.

${ }^{35}$ K. Jaspersas. Kaltès klausimas. Gerio kontūrai. Iš XX a. užsienio etikos / Sud. Br. Kuzmickas, Vilnius: Mintis, 1989, p. 262

${ }^{36}$ Podsakoff, P. M., MacKenzie, S. B., Paine, J. B., Bachrach, D. G., "Organizational Citizenship Behaviours: A Critical Review of the Theoretical and Empirical Literature and Suggestions for Future Research", Journal of Management, 1 January 2000; 26(3), p. 513-563.

${ }^{37}$ Edwards, J. R., Cable, D. M., “The Value of Value Congruence”, Journal of Applied Psychology, May 2009; 94(3), p. 654.

${ }^{38}$ Posner, B.Z., "Another Look at the Impact of Personal and Organizational Values Congruency", Journal of Business Ethics, 1 December 2010; 97(4), p. 535-541.
} 
performance and an intention to leave the organisation ${ }^{39}$. With an ambiguity of roles, the employee is faced with a shortage of role-related information, is not sure of their role, goals and responsibilities, and may be forced to choose a path of trial and error ${ }^{40}$. When roles are in conflict, the employee is unable to satisfy the requirements and expectations for all roles and experiences psychological conflict and stress ${ }^{41}$. Therefore, a conflict and ambiguity of roles has a dysfunctional effect on an individual and organisational level, including personal dissatisfaction and a reduced organisational efficiency ${ }^{42}$.

Specific operating methods like HUMINT lead to situations where intelligence officers have to choose behavioural models in a context that is often both vague and conflicting. Relying on their own assessment of the congruence of values in the situation and faced with potential vagueness and conflict of roles, the officer chooses the model of behaviour that, just as the authors of this article suggest, can be grounded on one of three strategies.

\section{Intelligence Officers' Behaviour: between Morals and National Interests}

In terms of empirical ethics, an individual makes a decision in reliance on reasoning and logic to assess the consequences of the decision ${ }^{43}$. Ergo, the ethical aspect of the assessment of decision-making and the conduct of an individual is a province of the rational domain of human activity. Disparities in moral evaluation occur as a result of the individual making moral decisions whilst analysing and resolving moral dilemmas, whose decisions are based on the moral attitudes of that individual ${ }^{44}$. Therefore, the cognitive moral development of an individual is the key distinctive characteristic of the individual

\footnotetext{
${ }^{39}$ Edwards, J. R., Cable, D. M., “The Value of Value Congruence”, Journal of Applied Psychology, May 2009; 94(3), p. 654; Rich, B. L., Lepine, J. A., Crawford, E. R., "Job Engagement: Antecedents and Effects on Job Performance", Academy of Management Journal, 1 June 2010; 53(3), p. 617-635; Naus, F., van Iterson, A., Roe, R.A., "Value Incongruence, Job Autonomy, and Organization-based Self-esteem: A Self-based Perspective on Organizational Cynicism", European Journal of Work and Organizational Psychology, 1 June 2007; 16(2), p. 195-219.

${ }^{40}$ Rizzo, J. R., House, R. J., Lirtzman, S. I., "Role Conflict and Ambiguity in Complex Organizations", Administrative Science Quarterly, 1 June 1970, p. 150-163.

${ }^{41}$ Ibid.

${ }^{42}$ Ibid.

${ }^{43}$ Kohlberg, L., The Philosophy of Moral Development Moral Stages and the Idea of Justice, 1981, San Francisco: Harper and Row.

${ }^{44}$ Kohlberg, L., Essays on Moral Development: Vol. 2. The Psychology of Moral Development: Moral Stages, Their Nature and Validity, 1984, Harper \& Row.
} 
level that affects the making of decisions ${ }^{45,46}$. According to Lawrence Kohlberg, cognitive moral development consists of three levels of personal moral maturity ${ }^{47}$ :

- Pre-conventional level, on which the individual distinguishes between right and wrong based on personal implications (such as reward, punishment or mutual gain);

- Conventional level, on which the right decisions are made on the basis of expectations of social groups (such as family, organisation);

- Post-conventional level, on which the concept of what is right is defined by common human values and universal moral norms. In this case, the individual makes decisions independently of group authority while following general principles.

Ethical behaviour and decisions are tied to higher-order moral reasoning $^{48}$. As was discussed in the section dealing with the premises of moral reasoning, the HUMINT method involves dual values, matters of value congruence and conflicting roles and ambiguity - all of this defines an atypical context in which the intelligence officer has to make moral decisions and choose ethical behaviour. Even if one is to follow generally accepted norms and values, this context breeds a moral dilemma; it should therefore be emphasised that a higher order of moral reasoning might involve breaking some of the norms or values. The authors of this article assume that, depending on the level of cognitive moral development, the intelligence officer may choose one of the following potential behavioural strategies:

- Refusal: post-conventional reasoning in line with socially accepted values and norms (such as 'tell the truth') may result in the intelligence officer refusing to apply the HUMINT method (in that case, the officer will change the course of action and use other methods instead);

- Reconciliation: a strategy grounded on the post-conventional level of reasoning in line with socially accepted values and norms, which is decisively affected by higher goals (such as the well-being and national security of the state vs risks that exist on an individual level). The of-

\footnotetext{
${ }^{45}$ Rest, J. R. \& Narvaez, D., “Summary-What's Possible?”, 1994, in J. R. Rest \& D. Narváez, eds., Moral Development in the Professions: Psychology and Applied Ethics, p. 213-224, Hillsdale, NJ: Lawrence Erlbaum.

${ }^{46}$ Trevino, L. K., Youngblood, S.A., "Bad Apples in Bad Barrels: A Causal Analysis of Ethical Decisionmaking Behavior", Journal of Applied Psychology, August 1990; 75 (4), p. 378.

${ }^{47}$ Kohlberg, L., Moral Stages and Moralization: The Cognitive-development Approach, Moral Development and Behavior: Theory Research and Social Issues, 1976, p. 31-53.

${ }^{48}$ Trevino, L. K., Youngblood, S.A., "Bad Apples in Bad Barrels: A Causal Analysis of Ethical Decisionmaking Behavior", Journal of Applied Psychology, August 1990; 75(4), p. 378.
} 
ficer who chooses this strategy consciously agrees to transgress certain norms and values for the sake of values that rank higher in the general hierarchy;

- Adjustment: a strategy based on the conventional level of reasoning when the officer need only follow the expectations of an authority (such as orders from superiors) to agree to apply the HUMINT method without having to deal with resolving a clash of values and norms. In this context, this type of reasoning could possibly be connected to the need to make decisions in a very short period of time, as well as gut judgement $^{49}$;

- Re-orientation: a type of behaviour grounded on a decision to apply the HUMINT method under pre-conventional reasoning; in other words, reward or gain on an individual level.

Each of the selected behavioural strategies potentially affects the outcomes on an individual, group, organisation and state level.

As was already noted in the discussion on the premises of moral reasoning and behaviour, questions of morality arise when the individual's decision and behaviour could benefit or harm others. Positive outcomes of intelligence officers' conduct are directly related to national security and, as discussed above, positive results on an individual and organisational level. On the other hand, just like premises of reasoning and behaviour, the negative consequences of the behaviour of intelligence officers, too, are quite ambiguous and merit a separate discussion.

Refusal. The intelligence officer's refusal to apply the HUMINT method by virtue of its contradicting the generally accepted values and norms is rooted in negative consequences to the state and organisation of a certain degree, such as lost opportunities or resources to train the employee. Nonetheless, on an individual level, this decision has to do with the potential short-lived discomfort in tackling a moral dilemma and assures the officer's status quo in terms of the values and norms that are recognised by them. Additional risk occurs if the officer decides to change their behavioural model in the course of applying the HUMINT model. For instance, if an emotional connection is established between the intelligence officer and their human sources of information, the officer might re-engage in moral reasoning and refuse to perform their professional duty, undermining both the intelligence operation and the intelligence institution and the national security of the state as well.

\footnotetext{
${ }^{49}$ Haidt, J., "The Emotional Dog and its Rational Tail: a Social Intuitionist Approach to Moral Judgment”, Psychological Review, October 2001, 108(4), p. 814.
} 
Reconciliation. There might be dual positive and negative consequences when the officer opts for a reconciliation strategy, agreeing to use the HUMINT method and transgresses some of the generally accepted moral norms of behaviour following the values of a higher level of hierarchy, such as national security and the well-being of society. By choosing this strategy of behaviour, the intelligence officer reconciles with the necessity to transgress some norm in favour of some long-lasting results of a different scale and the need to eliminate the bigger risk and negative consequences. That way, the officer embarks on a process of ethical decision making ${ }^{50}$, in which 'unethical' behaviour can be explained rationally after all of the potential alternatives and consequences have been evaluated.

Even though in reconciling and making the decision to personally apply the HUMINT method the officer serves the interests of national security, in the long run this need to trample values and norms could potentially to lead to several risks. For instance, routine reasoning and decision-making of this type could result in long-term psychological discomfort that could, in turn, bring greater psychosocial consequences or lead to a moral erosion of personality. If the forms of the intelligence officer's professional work used in the HUMINT method, meaning lies, manipulation, exploitation and other elements of unethical behaviour that occur with this method become the norm of conduct in their social setting, these elements of behaviour could be transferred to the internal environment of the intelligence organisation as well. This creates a destructive impact on the organisation's work just as it poses a threat to the national security of the state.

National security decision-makers need to obtain a premium intelligence product ${ }^{51}$, and the lack of ethics amidst intelligence professionals negatively affects the quality of the workforce and the work of the intelligence organisation. In their application of the HUMINT method, intelligence officers need to manipulate their own personal moral attitudes, reducing them to the extent that they do not interfere with the task at hand because the object of their professional work is to assure the interests of national security. In this regard, we could second the observation made by Edwin D. Godfrey that if ethical standards are reduced for the sake of an objective once, they can be reduced just as easily a second time or as many times as may be necessary. This creates a threat that the operations of the intelligence service will ignore any moral

\footnotetext{
${ }^{50}$ McDevitt, R., Giapponi, C., Tromley, C., "A Model of Ethical Decision-making: The Integration of Process and Content", Journal of Business Ethics, 1 June 2007; 73(2), p. 219-29.

${ }^{51}$ Andegg, M., Intelligence Ethics: A Key to Much Bigger Issues, p. 13, http://www.cgscfoundation.org/wpcontent/uploads/2015/05/Andregg-IntelligenceEthics-final.pdf.
} 
principles. In any case, the examples of the above risks have to do with negative implications both to the officer and the organisation and the state, making it necessary to observe, identify and adjust the model of the officer's behaviour if necessary.

Re-orientation. Another important moral problem is conformism of the intelligence officer, when the officer agrees to apply the HUMINT method at the expense of values and norms but makes this decision on the level of pre-conventional reasoning, on the basis of personal reward or gain. In other words, the officer makes the decision to become involved in HUMINT, but re-orients from the values of a higher hierarchy (such as those of national security) towards personal gain. The re-orientation strategy can be regarded as a kind of an artificial form of the reconciliation or adjustment strategies, one that is tightly related to conformism. From an ethical point of view, a conformist is someone who does not accept moral requirements as personal convictions but rather remains solely as an external control that demands or rewards obedience $^{52}$. Conformism as artificial adaptation to the environment - the opinion of an individual or a group, rules of conduct, form of relationship and other aspects - may be inevitable due to the need for specifics-driven continuous hypocrisy in fictitious relations with the sources of information. It is the above specifics that create in the midst of intelligence services room for conformists who find it easy to apply the HUMINT method, at the same time causing a risk of integration with commercial and closet conformists that could potentially threaten the operations of intelligence institutions and national security.

A commercial conformist is someone who, whilst demonstrating their morality, is driven by self-centred interests: compensation, recognition, praise, reward, career promise and other benefits. In some cases, the intelligence officer driven by personal egoism could exploit the human sources forcing them to trespass the boundaries of risk, consciously or otherwise. Considering that the interaction between intelligence officer and source takes place tête-à-tête, there is room for the intelligencer to interpret and present the information in their own way: the officer could belittle, glorify, distort or even falsify the information. This kind of situation has a clear illustration in the case of Yehuda Gill, a former Mossad employee, when in order to protect his reputation as a successful intelligence officer he began falsifying the information his source supplied, which almost resulted in war between Israel and Syria ${ }^{53}$.

\footnotetext{
${ }^{52}$ Stoškus, K., Bendravimas ir žmogaus dorumo lygmenys, Etikos etiudai, Vilnius, Mintis, 1979, p. 33-44.

${ }^{53}$ Shpiro, Sh., Speak No Evil: Intelligence Ethics in Israel, Ethics of Spying: A Reader for the Intelligence

Professional Vol. 2, Scarecrow Press, 2010, p. 62
} 
Commercial conformism can easily evolve into closet conformism, which basically constitutes a form of immoral behaviour. A closet conformist gives out the appearance of a moral person, using it to disguise their antihuman and antisocial intent. Employed by an intelligence service, this type of individual jeopardises the intelligence institution and the national security of the state alike. A closet conformist is apt to betray national interests for any kind of reason such as a lack of financial resources or recognition, family interests or conflicts at work. With closet conformism, betrayal is the product of a moral erosion of the individual rather than motives. The most prominent examples of conformists of this kind were the US CIA agent Aldricht Ames and the US FBI agent Robert Hanssen. The latter had spied for the Soviet Union and the Russian Federation for as many as 22 years.

Summing up the aspects of the intelligence officer that were covered in the previous sections, such as moral reasoning, premises, strategies and conclusions, an integrated mode of context and consequences of the choice of behavioural model of the intelligence officer can be drawn, as shown in Figure 1.

Behavioral model (context of choice)

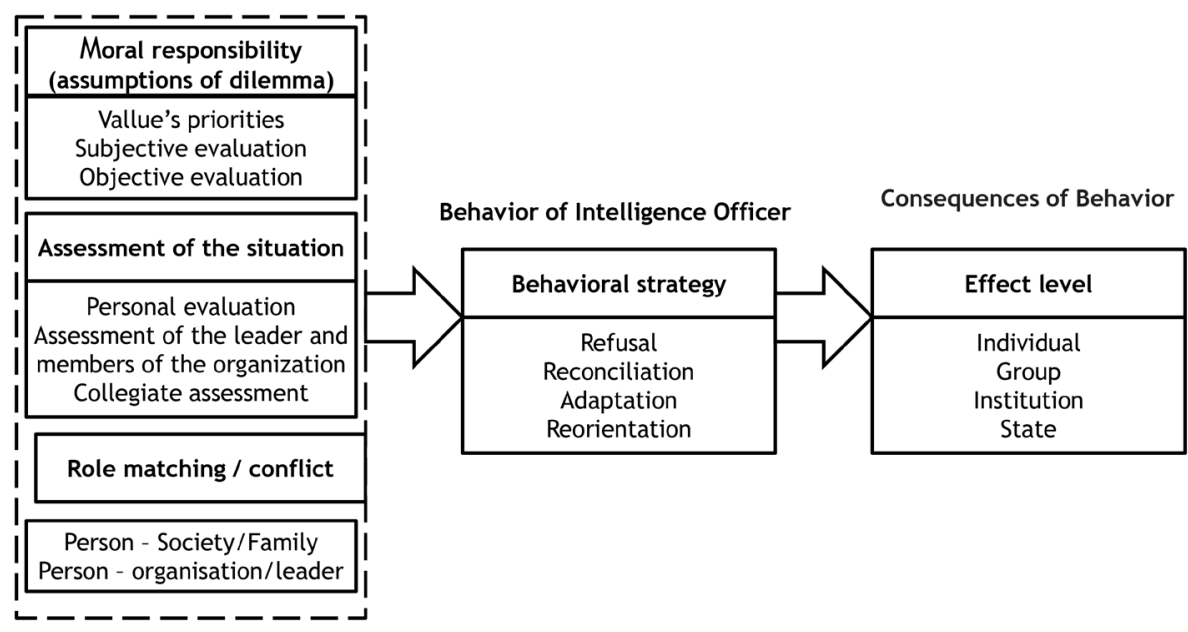

Figure 1. An Integrated Mode of the Context and Consequences of Choice of the behavioural model of the intelligence officer

Moral dilemmas in the behaviour of the intelligence officer are caused not only by national priorities or the complexity of value-based assessment but also by the political, psychological and organisational aspect of the officer's work. They are directly connected to the quality of the intelligence institution's operations, which is critical for ensuring the national security of the state. Eve- 
ry decision made by the intelligence officer can have negative moral and political consequences, affecting the individual security of a person and national security.

\section{Behaviour of Intelligence Officers: Instruments and Practice}

Considering the complicated context of the premises of moral reasoning and the potential negative consequences of behaviour to an individual, the organisation and the national security of the state, moral support and assistance to officers should be ingrained in the culture and practice of an organisation. Measures and principles used to that end can be divided into instruments and practices.

The intelligence officer's work with human sources of information is legally regulated as a general rule. On the other hand, one cannot identify the boundaries of law as those of moral responsibility, and therefore national legal systems do not stipulate how the intelligence officer must or can use human sources of information in terms of moral responsibility. Therefore, by not focusing enough on the ethical aspects of HUMINT operations, the intelligence service will not be able to identify the moral downfall of its intelligence officers due to continued moral harm in the line of duty, which is incompatible with typical moral attitudes ${ }^{54}$.

The work of intelligence institutions is a socially accepted operation that ensures national security and demands from intelligence officers specialist knowledge and competences to engage in it. Based on these two criteria of professional work, intelligence should be considered a profession. Like any other profession, apart from the aforesaid two components, intelligence operations must have a third: its own moral standards. Therefore, to be able to construct an appropriate model of the moral regulation of the officer's intelligence operations, intelligence as profession needs to be regulated not only by legislation but by moral standards. These standards should be reflected in the normative documents of intelligence institutions, such as a code of ethics. Legislation regulating intelligence operations provides what the service can do, and ethical regulation of the service's operations would serve as a moral beacon for the officers that they could follow in making moral decisions and preserving the

\footnotetext{
${ }^{54}$ Langan, J. P., Moral Damage and the Justification of Intelligence Collection from Human Sources, Ethics of Spying: A Reader for the Intelligence Professional Vol. 1, Scarecrow Press, 2006, p. 105.
} 
proportionality and rationality of action. Moral beacons should help the intelligence officer understand the boundaries of their moral responsibility that they should follow in their professional work. As a case in point, the underlying relationship between the intelligence officer and the human source of information in HUMINT operations has to be defined by clear professional ethics regulations outlining the limits of morally acceptable conduct. These regulations could help the intelligence officer retain an ability to distinguish between the intrinsic HUMINT behavioural model and the way the officer behaves at work, for instance in interacting with peers or superiors, as well as the behavioural model relevant to their personal life. This has endorsement from William M. Nolte, who argues that a moral framework is needed to protect the mental and moral health of intelligence officers ${ }^{55}$. Ethical regulations would define the principles of moral norms and guide the intelligence officer's behaviour just as they would allow drawing the boundaries of social tolerance towards intelligence institutions and identifying the compliance of these institutions to the state's national interests. Intelligence operations grounded on moral principles and norms would enjoy a higher degree of understanding amidst society and support from the public. Ergo, providing the necessary instruments would positively affect the intelligence institution and the state in handling national security matters.

The normative aspects of the operations could be enforced not only with instruments but through specific practices applied in an organisations' work. The vital mission of intelligence institutions (that of ensuring national security) as such is not a moral excuse for any sort of acts of intelligence institutions. Quite the opposite; this mission implies very high moral criteria for the staff of intelligence institutions, for society demands that its interests (security and well-being) be ensured by people of exceptional morals. This is why recruitment to intelligence services is subject to professional and very high moral requirements. Nonetheless, recruitment criteria in their own right are not a guarantee of ethics on the part of the intelligence services.

The main theme of intelligence operations should be the tell the truth principle. This principle should become the ethical foundation of the intelligence service's operations and provide moral protection both to the employee of the intelligence service and to the intelligence service per se. The rule of telling the truth should also become a guarantee of the public's trust in the intelligence institution and its commitment to carry out its professional duty of ensuring national security in good faith. At the same time, the intelligence institution should consider that the officer engaged in HUMINT operations is

${ }^{55}$ Nolte, W. M., “Ethics and Intelligence”, Joint Force Quarterly, Vol 54, 2009, p. 24. 
often forced to make split-second decisions ${ }^{56}$, which makes moral dilemmas all the more complicated. The institution should therefore strive to create professional working conditions where officers would be able to admit their mistakes due to ambiguous moral judgement and would not be afraid to accept blame. In other words, blame as a vital premise of personal responsibility would serve as a step towards the professional and moral development of the officer.

Such working conditions are a product of the established organisational culture. Many researchers of intelligence institution operations argue that the organisational framework of such institutions is not as important as their organisational culture ${ }^{57}$. This latter both affects the behaviour, mutual relations, worldviews and professional competences of the officers and shapes the quality of intelligence operations, which in turn defines success in ensuring national security within the limits of the competence of the intelligence institution. Moulding the organisational culture and the officer's behaviour alike - this is where responsible, ethical leadership really comes into play. Michael E. Brown et. $\mathrm{al}^{58}$ has noted that ethical leadership is based on the following three key principles: serving as a role model; treating people fairly; and guiding morals actively. David M. Mayer, Karl Aquino, Rebecca L. Greenbaum and Maribeth Kuenzi make the generalisation ${ }^{59}$ that the first two components of ethical leadership involve the desired qualities of a leader, such as honesty and reliability, while the third covers the aspect of a moral leader, where an ethical leader encourages normative behaviour and curbs the unethical conduct of subordinates via communication about ethics and active steps. In this respect, we have the role of intelligence officers as ethical leaders and the need to promote ethical leadership that would serve as a beacon for moral behaviour.

The practice of communication between intelligence institutions and the public merits separate discussion. HUMINT is usually subject to the requirement that the existence and the promoter of the operation be kept secret ${ }^{60}$; therefore, a society that demands more transparency often connects this method with, say, spying and covert operations - in other words, secret, hence

\footnotetext{
${ }^{56}$ Bailey, C. E., “The Intelligence Community Ethos: A Closely Regulated Profession”, International Journal of Intelligence Ethics, Vol 3. Number 2, 2012, p. 68

${ }^{57}$ Hastedt, G. P., Skelley, B. D., Intelligence in a Turbulent World: Insights from Organisational Theory, Intelligence Theory, Routledge, 2009, p. 127.

${ }^{58}$ Brown, M. E., Treviño, L. K., Harrison, D. A., "Ethical Leadership: A Social Learning Perspective for Construct Development and Testing", Organisational Behaviour and Human Decision Processes, 1 July 2005; 97(2), p. 117-34.

${ }^{59}$ Mayer, D. M, Aquino, K., Greenbaum, R. L., Kuenzi, M., "Who Displays Ethical Leadership, and Why does it Matter? An Examination of Antecedents and Consequences of Ethical Leadership", Academy of Management Journal, 1 February 2012; 55(1), p. 151-171.

${ }^{60}$ Ibid.
} 
unethical acts. Some people can respond to some forms of intelligence operations positively or give them moral justification by intuition, yet they will find it difficult to pinpoint the ethical grounds for such forms of operations with any degree of certainty ${ }^{61}$. This calls for raising society's awareness and educating the public in the field of the intelligence institution's operations, its course of action, functions, specifics and problems. One example of this type of practice is the academic and social activities of the CIA, which involves the intelligence institution publishing its available academic literature and publications on intelligence on the institution's official website.

\section{Conclusions}

Despite the sceptical attitude towards the compatibility between intelligence operations and moral principles, according to Jan Goldman, service in an intelligence institution should be seen as ethical, considering the fundamental mission of intelligence ${ }^{62}$. Under this approach, ensuring the interests of national security as the mission of the intelligence services equates to moral norms, which should justify any actions by intelligence officers in their own right. Nonetheless, one should note that the objective and tools of human activity differ, and ethics is an overarching domain of human relations, and so all activities - those of an individual and of the community alike, from the objectives to the implications - are subject to evaluation. Speaking of the relationship between intelligence and ethics, former CIA Director Stansfield Turner says that there is but one way to conduct an ethical assessment of the actions of the intelligence service. According to Turner, ethical actions are those acts by the intelligence service that can be justified in public, should they be revealed ${ }^{63}$. This relativist attitude towards the relationship between intelligence and ethics demands setting socially acceptable moral standards of intelligence operations. Furthermore, it needs noting that a service performing intelligence functions in a democratic society is a governmental institution that ensures the interests of the well-being and security of the public, and it is by virtue of this special mission that intelligence staff are obligated to abide by principles of conduct that are acceptable to the public. Moreover, the social moral standards that the employees of governmental institutions tasked with ensuring people's well-being and security have to follow are far above the average.

\footnotetext{
${ }^{61}$ Hulnick, A. S., Mattausch, D. W., Ethis and Motality in U.S. Secret Intelligence, Ethics of Spying: A Reader for the Intelligence Professional Vol. 1, Scarecrow Press, 2006, p. 40.

${ }^{62}$ Goldman, J., “Teaching About Intelligence”, Journal of U.S. Intelligence Studies, Vol 20, No 2, 2013, p. 79.

${ }^{63}$ Turner, S., Secrecy and Democracy: The CIA in Transition, Boston, Houghton Mifflin, 1985, p. 178.
} 
In this regard, the connections of the goals and objectives of intelligence as an institution and the interests of social security and well-being imply a duty for the service to follow socially acceptable ethical principles and norms. The specification of intelligence methods, and the shift of the intelligence services' operational priorities based on the geopolitical situation and the interests of national security, as well as the conflict of private and national interests defined by the nature of national security as a phenomenon, creates a certain degree of contradiction between the standards of intelligence operations and socially acceptable moral attitudes. Such specifics of the operations of intelligence services provoke both controversial judgement by the public and certain moral problems with regard to intelligence operations. Addressing the ethical aspect of HUMINT, Donaldas A. Petkus observes that an intelligence officer who lives by high moral attitudes and ethical norms could feel discomfort where the application of the HUMINT method drives them to choose a model of behaviour with the human source that they would consider unethical or amoral in personal life. Petkus quite reasonably raises the following questions ${ }^{64}$ : Is it desirable for officers to draw a line between professional practice and personal ethics? What is its long-term effect? Does this kind of practice cause the stress and erosion of moral standards? These questions are very difficult to answer for they require detailed studies, while the specifics of the intelligence services make subjects for such studies inaccessible. This kind of situation limits the intelligence service's ability to identify the internal problems of the organisation that could potentially become a threat to the employee, the intelligence institution and the national security of the state.

The highest moral requirements that apply to intelligence institutions obligate them to exercise particular care in controlling the work of their officers - especially those who use the HUMINT method for intelligence purposes. The intelligence institution expects that officers engaged in HUMINT will use unethical forms of conduct with regard to their human sources of information responsibly and will follow the principle of prudence and proportionality. Therefore, regardless of the interests of national security, intelligence services should set moral standards, demand and control compliance from and by the officers, observe the moral model of HUMINT operations applied by an officer, and adjust it as necessary.

To sum up, it should be noted that intelligence operations and ethics is not a subject that has broad coverage in scientific literature; this issue certainly

\footnotetext{
${ }^{64}$ Petkus, D. A., "Ethics of Human Intelligence Operations", International Journal of Intelligence Ethics, Vol. 1, No. 1, 2010, p. 107.
} 
lacks attention in Lithuania. This article provides a structured view of insights based on the scientific literature dealing with the context of an individual and organisational level, premises of moral reasoning that affect the behavioural strategies of choice, as well as their consequences on the individual, group, organisation and state level. An initial integral model of intelligence officer behaviour, context and consequences of the choice of behavioural model are drawn in reliance to the theoretical analysis contained in the article to possibly serve as a starting point for further structured discussion to take off. Morals are one of the critical aspects of the operations of intelligence institutions in ensuring national security. Considering that, despite the practical relevance of this subject, it still remains quite under-investigated, the authors of this article call for a continuation of the scientific discourse on the relationship between ethics and intelligence.

October 2017 